\title{
Genome-wide real-time PCR for West Nile virus reduces the false negative rate and facilitates new strain discovery
}

\author{
James F. Papin ${ }^{\mathrm{a}}$, Wolfgang Vahrson ${ }^{\mathrm{b}}$, Lindsay Larson ${ }^{\mathrm{b}}$, and Dirk P. Dittmer ${ }^{\mathrm{b},{ }^{*}}$ \\ aDepartment of Pathology, U. Oklahoma Health Sciences Center, Oklahoma City, $1100 \mathrm{~N}$. \\ Lindsay, Oklahoma City, OK 73104, Oklahoma, OK 73104 \\ bDepartment of Microbiology and Immunology, University of North Carolina at Chapel Hill, CB\# \\ 7290, 804 Mary Ellen Jones Bldg, Chapel Hill, NC 27599-7290
}

\begin{abstract}
West-Nile virus (WNV) causes significant morbidity and mortality worldwide. Transplant and transfusion recipients as well as the elderly are particularly at risk. WNV shows strain variation from season to season and from locale to locale. This poses a significant problem for diagnosis. Most assays use a single primer pair to detect WNV by QPCR, and can fail to detect novel stains. To overcome this limitation, a genome-wide, multiple primer-based real-time QPCR assay was developed for WNV. The same assay can be used for quantitation, viral variant discovery as well as for amplification of the entire viral genome using a single annealing temperature. It improves upon routine diagnosis as well as facilitates laboratory investigations of the pathology of WNV.
\end{abstract}

\author{
Keywords \\ real-time PCR; West Nile virus; TaqMan; qPCR
}

\section{Introduction}

Since its introduction in 1999, West Nile Virus (WNV) can be detected with a pattern of significant, recurring and persistent incidences in the U.S. Cases of human infection with WNV are reported regularly. Transmission requires a mosquito bite or blood transfusion (CDC, 2004; Hayes et al., 2005; Iwamoto et al., 2003; Pealer et al., 2003). West Nile virus (WNV) belongs to the Flaviviridae, a family of over 70 related viruses. More specifically, WNV is a member of the Japaneses Encephalitis (JE) serocomplex, which also includes JE virus, St. Louis encephalitis (SLE) virus, and Murray Vally enchephalitis (MVE) virus (Murphy et al., 1995). As with other flaviviruses, WNV is an enveloped single-stranded, positive sense RNA virus with a genome of approximately $11 \mathrm{~Kb}$ encoding for three structural genes and seven nonstructural genes. The genome is translated as a single polyprotein, which is subsequently cleaved by viral and cellular proteases into its final products. The earliest complete viral genome sequence for the U.S. epidemic was determined from the WNV-NY99 isolate (Lanciotti et al., 2002; Lanciotti et al., 1999). This

\footnotetext{
(C) 2010 Elsevier B.V. All rights reserved.

*Corresponding author: Tel: (919) 966-7960 fax: (919) 962-8103 ddittmer@med.unc.edu .

Publisher's Disclaimer: This is a PDF file of an unedited manuscript that has been accepted for publication. As a service to our customers we are providing this early version of the manuscript. The manuscript will undergo copyediting, typesetting, and review of the resulting proof before it is published in its final citable form. Please note that during the production process errors may be discovered which could affect the content, and all legal disclaimers that apply to the journal pertain.
} 
genome sequence formed the basis for the first WNV RNA-specific PCR assays (Lanciotti, Kerst, 2001; Lanciotti et al., 2000; Lanciotti et al., 1999; Shi, 2001; White et al., 2001).

In human patients infected naturally, WNV peripheral blood viral load is generally not sufficient to allow transmission back into mosquito vectors. Humans are thus the so-called "dead-end" hosts for this pathogen. Consistent with low-level peripheral viremia in humans, attempts to isolate live WNV from CSF or serum in culture were generally not successful. A single study with cancer patients infected experimentally found substantial viral loads in the peripheral circulation (Southam, Moore, 1954). This leaves PCR-based viral load determination as the only means to establish acute viral infection or to test blood units for the presence of the virus.

Since 2003, multiple cases of WNV transmission by blood transfusion have been confirmed (CDC, 2002; CDC, 2004). One donor positive for anti-WNV antibodies by an IgM capture ELISA, but the majority of donors who transmitted WNV had not seroconverted at the time of transmission. In contrast, all donor samples were found positive for WNV by TaqMan ${ }^{\mathrm{TM}}$ based real-time quantitative RT-PCR. The same holds true for clinical observations or experimental infections in non-human primates (Hukkanen et al., 2006; Ratterree et al., 2004; Wolf et al., 2006). WNV viremia precedes the IgM antibody response, thus direct viral load determination by real-time quantitative PCR (qPCR) is the method of choice for informing clinical decisions as well as public health measures.

Current real-time QPCR WNV assays rely on a single primer pair for viral load determination as first developed by Lanciotti and colleagues (Lanciotti et al., 2000; Papin et al., 2004b). They work exceptionally well. Yet, it was hypothesized by our laboratory that newly emergent WNV strains could have acquired mutations in the PCR primer-binding sites, which rendered them undetectable to even the best current assays. Furthermore, additional sequence information is often desirable to aid in the clinical diagnosis or epidemiological investigations, such as during outbreak inquiries. Thus far these two different applications, viral load determination and phylogenetic tracking, have necessitated two completely different assay formats (and twice the amount of sample). A viral-load assay for WNV is described that uses a single sample preparation/reverse transcription step and that combines accurate, high throughput quantitation with strain typing capabilities. To achieve this goal, a novel set of real-time qPCR primers was designed that can be used in parallel for singleplex viral load assays and that in combination span the entire WNV genome. RNA isolation/reverse transcription methods were optimized to maximize sensitivity as well as the number of replicates per sample.

\section{Methods}

\subsection{Virus strains}

A plaque-purified low passage ( $\leq 5$ passages on VERO cells) strain (OK03) was used, which was isolated from blue jay brains during the 2003 epidemic (Papin et al., 2004b), which belongs to US lineage I (Davis et al., 2005). NY99 flamingo isolate was used for comparison (Beasley et al., 2002). Both strains are neuroinvasive and cause $100 \%$ mortality in mice at $10^{3}$ pfu (Papin et al., 2005).

\subsection{RNA isolation and CDNA synthesis}

RNA was isolated using RNAzol (Tel-Test, Friendswood, USA) or RNA isolation kit (Qiagen, Valencia, USA) according to manufacturers recommendations. Total RNA was reverse transcribed in a $100 \mu \mathrm{l}$ reaction volume containing RNasin, and $0.3 \mu \mathrm{M}$ of random hexanucleotide primers (Applied Biosystems, Foster City, USA) according to manufacturers recommendations. The reaction mix was incubated sequentially at $42{ }^{\circ} \mathrm{C}$ for $45 \mathrm{~min}, 52{ }^{\circ} \mathrm{C}$ 
for $30 \mathrm{~min}$, and $70{ }^{\circ} \mathrm{C}$ for $10 \mathrm{~min}$. The reverse transcription reaction was stopped by heating to $95^{\circ} \mathrm{C}$ for 5 minutes. All liquid was then collected at the bottom of the tube by centrifugation at $16,873 \times \mathrm{g}$ for 3 minutes. Next, $0.5 \mathrm{U}$ RNase H (Invitrogen, Carlsbad, USA) was added, and the reaction was incubated at $37^{\circ} \mathrm{C}$ for $30 \mathrm{~min}$ and again heated to 95 ${ }^{\circ} \mathrm{C}$ for $5 \mathrm{~min}$. Afterwards, the cDNA pool was chilled on ice, collected at the bottom of the tube and stored at $-80^{\circ} \mathrm{C}$.

\subsection{Real-time quantitative PCR}

Real-time qPCR was conducted using 2xSYBR mix (Roche Applied Science, Indianapolis, USA) using a final primer concentration of $150 \mathrm{nM}$. Gradient Real-time qPCR was performed with an MJR Opticon2 unit with hot-start $\left(5 \mathrm{~min} 95^{\circ} \mathrm{C}\right)$ and the following cycling conditions $\left(15 \mathrm{sec} 95^{\circ} \mathrm{C}, 15 \mathrm{sec}\right.$ gradient $55-65^{\circ} \mathrm{C}, 15 \mathrm{sec} 68^{\circ} \mathrm{C}$ for 40 cycles). Cycle threshold $\left(\mathrm{C}_{\mathrm{T}}\right)$ values were determined by automated threshold analysis. QPCR was set up in a dedicated room using a RoBoGo ${ }^{\mathrm{TM}}$ pipetting robot (MWG, Alabama, USA) with liquid level sensing, allowing for a pipetting accuracy of $0.1 \mu \mathrm{l}$. All surfaces were cleaned daily with $10 \%$ bleach, and exposed to UV lights overnight. Designated gowns, gloves, and facemasks were worn for all work. Dissociation curves were recorded after each run and the amplified products were visualized by $2 \%$ agarose gel electrophoresis.

\subsection{PCR product cloning and sequence analysis}

PCR products were purified using Qiagen PCR extract kit (Qiagen, Valencia, USA). The ends were repaired using End-It repair kit (Epicentre, Madison, USA) and ligated to EcoRVcut, dephosporylated pbluescriptSKII+ (Stratagene, La Jolla, USA) at $14{ }^{\circ} \mathrm{C}$ overnight using T4 ligase (NEB, Ipswich, USA). Ligation mixes were transformed into DH5alpha bacteria and plated on IPTG/X-gal plates (Invitrogen, Carlsbad, USA). Multiple positive clones were sequenced in both directions using M13 forward and reverse primers. The complete sequence of WNV OK03 has been deposited in genbank (accession number EU155484).

\subsection{SNP mapping}

84 complete WNV genomes were aligned to the NY-99 flamingo isolate (accession\# AF196835) and identified all SNPs using Sequencer v4.8 (Gene Codes Corp., Ann Arbor, USA). The number of intervening nucleotides between any two adjacent SNPs was calculated. Graphs were produced in R version 2.5.1.

\section{Results}

\subsection{A genome-wide SNP map of WNV evidences substantial variation}

To test the hypothesis that single nucleotide polymorphisms (SNPs) are present in recent WNV isolates and that SNPs may be present in any single one PCR primer binding site that is used for diagnosis, genbank was queried. 1,628 SNPs out of 11,029 nucleotide positions were found by BLAST search of the prototypical lineage I strain AF196835 (Figure 1A). Of those 82 sequences the medium number of SNPs per genome was 34 with a range of 0-499 SNPs. The SNPs were distributed evenly across the genome, except for the $3^{\prime}$ and 5' UTR regions (Figure 1B, D), which exhibited a relative paucity of SNPs. The E orf, too, contained numerous SNPs, which were distributed across the length of the orf (Figure 1C). This is a conservative estimate, since only genbank entries classified as containing complete WNV genome sequences were included in our alignment and of those only $n=82$ sequences with less than 500 mismatches (Figure 1F). For instance, strain AF196835 shows more than 2000 vis-à-vis strains belonging to other lineages such as lineage II, AY532665; lineage III, AY765264; lineage IV, AY277251; and lineage V, DQ256376). Moreover, strains classified 
as lineage I-B (D00246), show more than 1000 mismatches when aligned against the AF196835 sequence.

To gain a more detailed view at the SNP distribution, the nucleotide distances between any two adjacent SNPs were calculated (Figure 1E). The mean distance between any two SNPs in the WNV genome was 6.75 nucleotide with a ${ }^{95} \mathrm{CI}$ of $6.46-7.05$ and a range of $0-54$ nucleotides. Since a QPCR amplicon averages 90-200 nucleotides, it can be expected that diagnostic tests based upon only a single PCR assay will, sooner or later, fail because of SNPs in either one of the primer or the probe binding sites.

The 5'UTR up to nucleotide 420 and the $3^{\prime}$ UTR up to nucleotide -513 contained large inter-SNP regions, indicative of sequence conservation. This was expected since these regions are conserved among WNV and other flaviviruses in general. Both St. Louis encephalitis virus (SLE) and Japanese encephalitis (JEV) share extensive sequence identity in the UTR regions of up to 81\% for SLE isolate BeAn 247377 (accession \# EF158067) and up to 78\% for JEV isolate K01-JN (accession\# AY965851) for the 5' UTR, respectively. Hence, for the purpose of differential WNV detection, primers that target the UTR regions are expected to have low specificity.

In the U.S. the possibility of misclassifying an infection as SLE rather than WNV raises concerns. Additionally, viral UTRs should not be selected as targets for diagnostic PCR probes due to the fact that UTR regions exhibit extensive and stable secondary structures. For the purpose of WNV detection, these may not be efficiently transcribed by reverse transcriptase or not unfold completely during the short denaturation step of recent "fast" real-time QPCR protocols. Hence, primers that target the UTR regions are expected to have low sensitivity. In sum, there are few absolutely conserved regions in the WNV genome and targeting them may not yield the best assay. It can be expected that there exist WNV sequence variants that escape detection with current single primer-pair-based assays.

\subsection{A novel set of WNV primers validated by annealing temperature profiling}

One approach to overcome potential false negative results caused by single mutations within any viral genome is to use multiple primers against the same virus. To test this hypothesis a panel of novel WNV-specific QPCR primers were developed with equal sensitivity as well as an integrated, high throughput assay format that reduce greatly false negative rates.

The chief concern when using multiple primers against the same target is that primers may exhibit varying annealing temperatures and thus cannot be combined on a single plate in a 96 or 384 well format. "PrimeTime" is based on Primer3 (Rozen, Skaletsky, 2000) to design multiple primers against WNV that share the same melting temperature $\left(\mathrm{T}_{\mathrm{m}}\right)$ and are compatible with each other. The initial primer design strategy which was used imposed no limitations as to the location of a given primer, it only required strict adherence to $T_{m}$ and universal primer design parameters (Papin et al., 2004a). This approach identified multiple primers across the WNV genome (Table 1).

QPCR optimization typically evaluates primer concentration, $\mathrm{Mg}^{2+}$ concentration and annealing temperature. First, the influence of the primer concentration was evaluated. All primers yielded single QPCR products with comparable efficiency $\left(\mathrm{K}_{\mathrm{eff}}\right.$ ) at $150 \mathrm{nM}$ final concentration, consistent with our prior experience using real-time QPCR arrays of $>80$ primers for human herpesviruses (Dittmer, 2003; Dittmer et al., 2005; Fakhari, Dittmer, 2002; Hilscher et al., 2005). Adjusting reagent conditions, such as $\mathrm{Mg}^{2+}$ concentration individually for each primer pair is impractical as it limits high throughput, automated analyses with multiple primers per target. It was not necessary here, since all primer pairs designed according to our parameters performed equally at a given $\mathrm{Mg}^{2+}$ concentration (data 
not shown). Therefore, the reagents provided in the commercial 2x SYBR mix were used. It canhypothesized, however, that one reason for decreased primer pair efficiency was a suboptimal annealing temperature under our QPCR conditions. $\mathrm{T}_{\mathrm{m}}$ predictions (Cantor, Schimmel, 1980) as provided by most primer design programs are not accurate, since the exact salt concentrations and buffer composition of most commercial QPCR reagents are not available. To test this hypothesis the gradient feature of the Opticon2 (MJR research/Biorad Inc.) real-time QPCR unit was used, which combines gradient PCR with the capability to record product accumulation quantitatively in real-time in the standard 96 well format. Hence, an annealing temperature dependent change in performance can be quantified on the same plate without post-PCR processing. Next a gradient annealing step of $55^{\circ} \mathrm{C}$ to $65^{\circ} \mathrm{C}$ for $15 \mathrm{sec}$. followed by a $68^{\circ} \mathrm{C} 15 \mathrm{sec}$. extension step, followed by fluorescence measurements, followed by a $94^{\circ} \mathrm{C} 10 \mathrm{sec}$ denaturing phase was employed. Fluorescence in each well was always measured at the same temperature. Hence, the resulting CT values reflect primarily differences in annealing efficiency. Other factors include primer extension efficiencies, the formation of primer dimmers, the formation of primer hairpins, template stability (including GC content), and template secondary structure (such as hairpin formation), among others, but not temperature dependencies during the extension phase or dye intercalation. Using automation, the optimal annealing temperature for sixteen primers pairs across six temperature points were determined at the same time. Most combinations of primers with a Primer3-predicted $\mathrm{T}_{\mathrm{m}}$ of $60^{\circ} \mathrm{C}$ showed amplification at $60^{\circ} \mathrm{C}$, but that temperature profiles varied considerably among individual primer pairs. Figure 2, panel A exemplifies a very efficient primer pair, as indicated by a median $\mathrm{CT}_{\text {median }}=10$ with little variation across the annealing temperature range. Figure 2, panel B shows a less efficient primer pair, as indicated by $\mathrm{CT}_{\text {median }}=13.5$, but with likewise little variation across the annealing temperature range. Figure 2, panel $\mathrm{C}$ shows a still less efficient primer pair, as indicated by $\mathrm{CT}_{\text {median }}=23.5$. It showed little variation across a wide annealing temperature range. By contrast, Figure 2, panel D shows a primer pair with a strong annealing temperature dependence as evidenced by a continuously changing CT between the lowest and highest annealing temperature. Figure 2, panel E shows a primer pair with a higher annealing temperature dependence. It failed to function above $64^{\circ} \mathrm{C}$. In sum, many primer combinations functioned equally efficiently within $\pm 2^{\circ} \mathrm{C}$ of their predicted $\mathrm{T}_{\mathrm{m}}$. Thus assays using multiple primer pairs against the same target, WNV, can be combined on the same instrument and 96 or 384 well plate.

After 40 cycles, all products for a given primer pair yielded the same size single band on an agarose gel and the same single peak melting temperatures (data not shown). This was expected since the primer design program incorporated a BLAST (Altschul et al., 1997) step, which excluded primers that bound anywhere other than the intended targets (Dittmer et al., 2005). This evidence confirms that a change in annealing temperature did not yield to a change in product, but reflected purely the efficiency of primer annealing.

Absolute quantitation using an external standard is required for viral copy number determination, as amplification efficiencies between primer pairs can vary considerably. Of note, the two worst performing primer pairs (Figure 2, C and E) also yielded considerably longer qPCR products of $2651 \mathrm{bp}$ and $2282 \mathrm{bp}$, respectively, which under fast qPCR cycling protocols as are used here (extension $\leq 30 \mathrm{sec}$ ) are associated with lower qPCR efficiency. A linear relationship ( $\mathrm{p} \leq 0.005$, by regression analysis) between amplicon length and median CT (Figure 3) was evident for amplicon lengths above $500 \mathrm{bp}$. For amplicon length below $500 \mathrm{bp}$, performance in qPCR was not dependent on amplicon length. The degree of annealing temperature variation was not dependent on amplicon length, since large interquartile differences were observed for the smallest (42 bp) as well as for larger (486 bp, $1042 \mathrm{bp}, 2281 \mathrm{bp}$ ) amplicons. This shows that amplicon length can limit assay sensitivity for 
the detection of WNV and that an amplicon size of $500 \mathrm{bp}$ or less is associated with higher sensitivity.

\subsection{An optimized, equal amplicon size, equal annealing temperature, and equal efficiency set of WNV primers for viral load determination and phylogenetic analysis}

To address the issue of amplicon length dependent changes in primer efficiency, i.e. assay sensitivity, a subset of real-time qPCR primer pairs were chosen that all yielded a 400bp product (Figure 4A), and that exhibit a temperature invariant annealing temperature profile around $60 \pm 5^{\circ} \mathrm{C}$ (data not shown) under rapid qPCR cycling conditions. An amplicon length of $400 \mathrm{bp}$ was chosen because (a) these can be easily purified by commercial, highthroughput resin-based methods, while smaller amplicons such as the typical $\leq 90 \mathrm{bp}$ TaqMan $^{\mathrm{TM}}$ amplicons do not bind efficiently to DNA affinity resins (Qiagen, and Promega product information and unpublished observation); and (b) direct sequencing of a $400 \mathrm{bp}$ PCR product yields enough information for strain typing and phylogenic tree construction with reasonable boostrap values, while the sequence information contained within $<100 \mathrm{bp}$ amplicons does not (Whitby et al., 2003).

None of the primers showed substantial cross reactivity to human cDNA (data not shown). More importantly, even though one individual primer pair may anneal theoretically somewhere on the human genome, the pair combinations shown in Figure 4A do not yield any product when used on human cDNA. The reason is that rapid real-time qPCR conditions as in Figure 4A do not produce efficiently amplification products larger than $1000 \mathrm{bp}$ and, based on BLAST search, no two primers used in Figure 4A annealed on the human genome within even 10,000 bp of each other (data not shown).

By using any three primer pairs from this collection instead of a single primer triplicate repetition assay format, the false negative rate due to SNPs in one of the primer binding sites can be reduced 6 fold, while still employing multiple independent QPCR reactions per sample. In a decision model based on maximal sensitivity, such as to exclude any possibly WNV positive blood samples, a single positive amplification would cause a sample to be considered positive. In a decision model weighted towards specificity, such as to exclude samples that may contain a related flavivirus, three positive amplifications would cause a sample to be coded positive.

Should the phylogenic information gained from $400 \mathrm{nt}$ not suffice for accurate typing, this set of WNV QPCR primers can be combined to yield larger PCR products that cover $80 \%$ of the WNV genome (Figure 4B) without change in annealing temperature. This approach was used to determine the complete sequence of WNV OK03, which has been deposited in genbank (accession number EU155484). This allows for the sequence determination of virtually the entire viral genome using the same reagents and annealing temperature as used for WNV viral load determination. The only change that is necessary is an increase in the extension time from $30 \mathrm{sec}$ to $120 \mathrm{sec}$. For completeness, the primer combinations indicated in Figure $4 \mathrm{C}$ can be used to amplify the entire viral genome using a common annealing temperature of $60^{\circ} \mathrm{C}$ and an extension time of 60 seconds. PCRs using first primer (position 1) and the last primer (position 10,876) require an annealing temperature of $55^{\circ} \mathrm{C}$.

Typically viral load assays are conducted as replicate measurements of the same assay/ primer pair. Here, the same number of reactions are run but instead of one primer pair multiple different, but annealing temperatures and $\mathrm{K}_{\mathrm{eff}}$-compatible primer pairs, such as introduced in Figure 4 are used. This will decreases the false negative rate due to nucleotide variation in the target sequences of any primer pair. This is particularly applicable to viral pathogens with seasonal patterns of incidence, such as WNV, since from one season to the next multiple adoptive mutations can be expected (Davis et al., 2003; Davis et al., 2005). 


\subsection{PCR volume optimization contributes significantly to assay sensitivity}

As the next step in optimizing high sensitivity, high specificity real-time qPCR assays for WNV, qPCR volume and input to reaction ratio were evaluated. As expected more sample per qPCR correlated with higher assay sensitivity, which here is indicated by lower cycle threshold (CT) numbers (Figure 5A). However, the relationship was not linear, but rather followed a power decay function. In conclusion, larger reaction volumes ultimately lead to less efficient heat transfer and thus less efficient PCR. The ratio of input sample to total reaction volume was more important than overall reaction volume, such that PCRs comprising only $20 \%$ of input sample were much more sensitive (as indicated by lower CT volumes) than PCRs comprising $42 \%$ input sample, even though the total amount of sample was higher in the latter. At $42 \%$, the cDNA reaction buffer components interfere with the QPCR buffer components leading to decreased PCR efficiency.

Quadruplicate qPCR yielded standard deviations (SD) of $\leq 1 \mathrm{CT}$ unit, or $\leq 2$-fold, regardless of sample volume. This establishes that quadruplicate measurements suffice to distinguish two-fold differences in WNV viral load. In this case, too, a power decay function best fit the data, demonstrating that lower sample volumes were associated with reduced assay accuracy. The loss in assay accuracy was likely due to increased pipetting error at low volumes. In sum, an input sample volume of $20 \mu \mathrm{l}$ in a total qPCR volume of $100 \mu \mathrm{l}$ yielded the most sensitive and most accurate real-time qPCR assay for WNV.

\subsection{Maximum assay sensitivity by using high volume reverse transcription}

Three commercial kits used to isolate WNV RNA were compared: Viral RNA (Qiagen), HighSensitivity (Qiagen), and viral RNA (Zymogen). All three kits were column-based. It can be presumed that the column binding capacity to be in excess of any amount of viral RNA that is found in bodily fluid samples such as plasma, whole blood or CSF. For tissue samples (bird, biopsy), previously a modified Triazol ${ }^{\mathrm{TM}}$ (Sigma) procedure (Papin et al., 2004b) was used, which has a higher capacity than these column-based kits and eliminates the risk of overloading as associated with resin/column-based RNA isolation. Furthermore, a prior reverse transcription assay (Papin et al., 2004b) was compared to the new highcapacity cDNA kit (Applied Biosystems). The goal was to arrive at a method that maximizes the number of viral genome cDNA equivalents per well of the QPCR reaction.

The main differences between the different isolation methods were the maximal input volume and optimal output volumes, which result in the dilution of RNA. Table 1 traces the effects of volume dilution starting from a theoretical concentration of 1000 copies $/ \mathrm{ml}$. Combining high sensitivity/high input RNA isolation with a high capacity cDNA kit yielded the most copies (50) as input for qPCR and the most number of possible replicates (nine +one). If less than $1000 \mu \mathrm{l}$ input material was available, a low elution volume combined with customary low volume RT reaction yielded the most copies (12) as input for qPCR while still allowing triplicate measurements (three+one). Of note the high-sensitivity/high yield RNA-isolation/reverse transcription combination resulted in a relative amplification of target copy number during the reverse transcription step. Assuming 1 copy/ $\mu \mathrm{l}$ input (or $10^{3}$ copies/ml titer), after RNA isolation/reverse transcription high yield/high capacity RT concentrated the RNA to $2.5 \mathrm{copies} / \mu \mathrm{l}$, while all other combinations diluted the input down to as much as 0.35 copies/ $\mu l$ in the worst case.

\section{Discussion}

Absent PCR inhibitors, the most likely source of false negative results for the diagnosis of RNA viruses, like WNV, is strain variations in the primer target sequence. One strategy to account for strain variation is to use redundant primers or special PCR conditions, such as 
step-down PCR, which allow the primers to anneal to variant targets. This approach invariably leads to loss of specificity and may necessitate post-PCR analysis steps. An alternative approach uses multiple primers against different target sequences of the WNV genome in parallel under highly stringent qPCR conditions.

A potential problem with using multiple primers is that they may have very different optimal annealing temperatures. This sparked the development of independently temperature regulated qPCR systems and gradient PCR. In the case of WNV primers were designed that do not require specialized equipment because they share the same annealing temperature and $\mathrm{Mg}^{2+}$ dependencies. Depending on the experimental design these primer either yield multiple unit size ( $400 \mathrm{bp}$ ) amplicons of equal qPCR efficiency $\mathrm{K}_{\text {eff }}$ targeted against random locations of the WNV genome, or they can be combined to yield directed, overlapping amplicons, which span the entire WNV genome.

To measure primer annealing efficiency (Figure 2), a gradient annealing step was used followed by a high temperature extension step to optimize polymerase activity, followed by fluorescence measurements at high temperature to minimize background. This protocol results in reliable annealing temperature determination for a given reagent mix. Annealing temperature did not depend on primer or target concentration (data not shown). It has been shown previously that raising the annealing temperature from the universal, two-step cycling conditions of $60^{\circ} \mathrm{C}$ to $62^{\circ} \mathrm{C}$, absent any other changes, lowered the rate of false-positive signals for primer pairs with equal efficiency at higher temperature (Hilscher et al., 2005), even though the primers were designed using TaqMan ${ }^{\mathrm{TM}}$ assay parameters (Applied Biosystems), which specify an annealing temperature of $60^{\circ} \mathrm{C}$. Alternatively, a gradient twostep protocol could be used to optimize the annealing temperature. This would use the same gradient annealing step of $55^{\circ} \mathrm{C}$ to $65^{\circ} \mathrm{C}$ for 30 seconds, followed by fluorescence measurements at the annealing temperature, followed by a $94^{\circ} \mathrm{C} 10$ seconds denaturing phase. Fluorescence would be measured at different temperatures and the resulting quantitation would reflect differences in primer annealing efficiency as well as temperature dependencies of both the polymerase and of the dye intercalation. The latter experimental design, while also arriving at optimal conditions, does not lend itself to rational explanation of the contribution of individual parameters to the overall reaction.

It was shown previously that an intercalating dye-based real-time QPCR assay is as sensitive as TaqMan ${ }^{\text {TM}}$-based real-time QPCR for WNV (Papin et al., 2004b). The use of an intercalating dye such as SYBRgreen ${ }^{\mathrm{TM}}$ as a method of detection has three principal advantages. First, it is more economical, since no doubly-labeled primer has to be synthesized and SYBR-containing commercial 2x qPCR mixes cost the same as non$\mathrm{SYBR}^{\mathrm{TM}_{\text {-containing commercial }} 2 \mathrm{x} \text { qPCR mixes. Second, SYBR }}{ }^{\mathrm{TM}}$-based qPCR can detect WNV strain variants with mutations in the target site, which prevent annealing of the TaqMan $^{\mathrm{TM}}$ probe (Papin et al., 2004b). Third, SYBR ${ }^{\mathrm{TM}}$-based qPCR no longer requires Taqpolymerase-associated 5'nuclease activity and can be used with 3'proof-reading ("highfidelity") polymerases as well as polymerases that are active a higher extension temperatures.

Clearly, there is a trade off between sensitivity and specificity. The design described above, which incorporates a BLAST search of primer pairs rather than single primers, found them to be highly specific for WNV. The exception here is primer 10881r, since this primer marks the $3^{\prime}$ end of WNV, which of course is conserved among many flaviviruses. In case of true cross reactivity, our method of using multiple WNV primer pairs in parallel against the same sample will yield a discordant read-out and thus alert the operator to the possibility of cross reactivity. By contrast a simple, single primer-pair based assay either fails completely (in 
case of sequence variation of a new WNV isolate) or yields a false positive in case of cross reactivity to a related flavivirus.

In addition to novel primer sets, other aspects of assay design were optimized. Careful optimization of the pre-PCR steps can boost sensitivity by as much as 20 fold (table 2). Since column-based RNA purification protocols lose efficiency if the elution volume is reduced, scaling up the RT reaction to accommodate $50 \mu \mathrm{l}$ of input RNA provides the best approach to maximize sensitivity. Similarly, optimizing the qPCR volume (Figure 5) contributes to overall assay sensitivity.

Currently many real-time qPCR assays for WNV viral load determination are in use and many have been adopted for high throughput screening (Eisler et al., 2004; Lanciotti et al., 2000; Papin et al., 2004b; Shi, 2001; Tewari et al., 2004; Vanlandingham et al., 2004). Still, they can be improved upon. As WNV incidence rates in the U.S.A. change from an epidemic pattern to a more variable and more seasonable endemic pattern, the new assay format presented here may prove its utility. The blood supply for the general population is not screened for WNV, which reflects primarily economic considerations (Busch et al., 2005; Stramer et al., 2005). However, major transplant centers screen donor blood and organs used in transplantation, since WNV can cause serious illness and mortality in immune compromised patients (Armstrong et al., 2003; Cushing et al., 2004; Hayes et al., 2005; Iwamoto et al., 2003; Murtagh et al., 2005; Pealer et al., 2003). The required throughput is lower. The need for increased sensitivity and the need to detect newly emerging strain variants can be filled with the genome-wide targeted real-time qPCR assay presented here.

\section{Acknowledgments}

Many thanks to Rebecca Hinds-Boykin and Chelsey Hilscher for technical help, as well as Blossom Damania, Error! Reference source not found. and Luciana Leopold for critical reading of the manuscript. This work was supported NIH. J. Papin was supported by NIH training grant AI07364.

\section{References}

Altschul SF, Madden TL, Schaffer AA, Zhang J, Zhang Z, Miller W, Lipman DJ. Gapped BLAST and PSI-BLAST: a new generation of protein database search programs. Nucleic Acids Res. 1997; 25:3389-402. [PubMed: 9254694]

Armstrong WS, Bashour CA, Smedira NG, Heupler FA, Hoeltge GA, Mawhorter SD, Sudheendra V, Gordon SM. A case of fatal West Nile virus meningoencephalitis associated with receipt of blood transfusions after open heart surgery. Ann Thorac Surg. 2003; 76:605-7. [PubMed: 12902115]

Beasley DW, Li L, Suderman MT, Barrett AD. Mouse neuroinvasive phenotype of West Nile virus strains varies depending upon virus genotype. Virology. 2002; 296:17-23. [PubMed: 12036314]

Busch MP, Caglioti S, Robertson EF, McAuley JD, Tobler LH, Kamel H, Linnen JM, Shyamala V, Tomasulo P, Kleinman SH. Screening the blood supply for West Nile virus RNA by nucleic acid amplification testing. N Engl J Med. 2005; 353:460-7. [PubMed: 16079369]

Cantor, CR.; Schimmel, PR. Biophysical Chemistry: The Behavior of Biological Macromolecules. Freeman; New York: 1980.

CDC. West Nile Virus Activity - United States, July 31-August 7, 2002, and Louisianna, January 1August 7, 2002. MMWR Morbidity, Mortality Weekly Report. 2002; 51:681-683.

CDC. Transfusion-associated transmission of West Nile virus--Arizona, 2004. MMWR Morb Mortal Wkly Rep. 2004; 53:842-4. [PubMed: 15371966]

Cushing MM, Brat DJ, Mosunjac MI, Hennigar RA, Jernigan DB, Lanciotti R, Petersen LR, Goldsmith C, Rollin PE, Shieh WJ, Guarner J, Zaki SR. Fatal West Nile virus encephalitis in a renal transplant recipient. Am J Clin Pathol. 2004; 121:26-31. [PubMed: 14750237] 
Davis CT, Beasley DW, Guzman H, Raj R, D’Anton M, Novak RJ, Unnasch TR, Tesh RB, Barrett $\mathrm{AD}$. Genetic variation among temporally and geographically distinct West Nile virus isolates, United States, 2001, 2002. Emerg Infect Dis. 2003; 9:1423-9. [PubMed: 14718086]

Davis CT, Ebel GD, Lanciotti RS, Brault AC, Guzman H, Siirin M, Lambert A, Parsons RE, Beasley DW, Novak RJ, Elizondo-Quiroga D, Green EN, Young DS, Stark LM, Drebot MA, Artsob H, Tesh RB, Kramer LD, Barrett AD. Phylogenetic analysis of North American West Nile virus isolates, 2001-2004: Evidence for the emergence of a dominant genotype. Virology. 2005

Dittmer DP. Transcription profile of Kaposi's sarcoma-associated herpesvirus in primary Kaposi's sarcoma lesions as determined by real-time PCR arrays. Cancer Res. 2003; 63:2010-5. [PubMed: 12727810]

Dittmer DP, Gonzalez CM, Vahrson W, DeWire SM, Hines-Boykin R, Damania B. Whole-genome transcription profiling of rhesus monkey rhadinovirus. J Virol. 2005; 79:8637-50. [PubMed: 15956606]

Eisler DL, McNabb A, Jorgensen DR, Isaac-Renton JL. Use of an internal positive control in a multiplex reverse transcription-PCR to detect West Nile virus RNA in mosquito pools. J Clin Microbiol. 2004; 42:841-3. [PubMed: 14766868]

Fakhari FD, Dittmer DP. Charting Latency Transcripts in Kaposi's Sarcoma-Associated Herpesvirus by Whole-Genome Real-Time Quantitative PCR. J Virol. 2002; 76:6213-23. [PubMed: 12021355]

Hayes EB, Komar N, Nasci RS, Montgomery SP, O’Leary DR, Campbell GL. Epidemiology and transmission dynamics of West Nile virus disease. Emerg Infect Dis. 2005; 11:1167-73. [PubMed: 16102302]

Hilscher C, Vahrson W, Dittmer DP. Faster quantitative real-time PCR protocols may lose sensitivity and show increased variability. Nucleic Acids Res. 2005; 33:e182. [PubMed: 16314296]

Hukkanen RR, Liggitt HD, Kelley ST, Grant R, Anderson D, Beaty BJ, Marlenee NL, Hall RA, Bielefeldt-Ohmann H. Comparison of commercially available and novel West Nile virus immunoassays for detection of seroconversion in pig-tailed macaques (Macaca nemestrina). Comp Med. 2006; 56:46-54. [PubMed: 16521859]

Iwamoto M, Jernigan DB, Guasch A, Trepka MJ, Blackmore CG, Hellinger WC, Pham SM, Zaki S, Lanciotti RS, Lance-Parker SE, DiazGranados CA, Winquist AG, Perlino CA, Wiersma S, Hillyer KL, Goodman JL, Marfin AA, Chamberland ME, Petersen LR. Transmission of West Nile virus from an organ donor to four transplant recipients. N Engl J Med. 2003; 348:2196-203. [PubMed: 12773646]

Lanciotti RS, Ebel GD, Deubel V, Kerst AJ, Murri S, Meyer R, Bowen M, McKinney N, Morrill WE, Crabtree MB, Kramer LD, Roehrig JT. Complete genome sequences and phylogenetic analysis of West Nile virus strains isolated from the United States, Europe, and the Middle East. Virology. 2002; 298:96-105. [PubMed: 12093177]

Lanciotti RS, Kerst AJ. Nucleic Acid Sequence-Based Amplification Assays for Rapid Detection of West Nile and St. Louis Encephalitis Viruses. Journal of Clinical Microbiology. 2001; 39:45064513. [PubMed: 11724870]

Lanciotti RS, Kerst AJ, Nasci RS, Godsey MS, Mitchell CJ, Savage HM, Komar N, Panella NA, Allen BC, Volpe KE, Davis BS, Roehrig JT. Rapid Detection of West Nile Virus from Human Clinical Specimens, Field-Collected Mosquitoes, and Avian Samples by a TaqMan Reverse TranscriptasePCR Assay. Journal of Clinical Microbiology. 2000; 38:4066-4071. [PubMed: 11060069]

Lanciotti RS, Roehrig JT, Deubel V, Smith J, Parker M, Steele K, et al. Origin of the West Nile virus responsible for an outbreak of encephalitis in the northeastern United States. Science. 1999; 286:2333-2337. e. [PubMed: 10600742]

Murphy F, Fauquet C, Bishop D, Ghabrail S, Jarvis A, Martelli G, Mayo M, Summers M. Virus Taxonomy, classification and nomenclature of viruses. Arch. Virology. 1995; 10:1-58.

Murtagh B, Wadia Y, Messner G, Allison P, Harati Y, Delgado R. West Nile virus infection after cardiac transplantation. J Heart Lung Transplant. 2005; 24:774-6. [PubMed: 15949740]

Papin J, Vahrson W, Hines-Boykin R, Dittmer DP. Real-time quantitative PCR analysis of viral transcription. Methods Mol Biol. 2004a; 292:449-80. [PubMed: 15507725]

Papin JF, Floyd RA, Dittmer DP. Methylene blue photoinactivation abolishes West Nile virus infectivity in vivo. Antiviral Res. 2005; 68:84-7. [PubMed: 16118025] 
Papin JF, Vahrson W, Dittmer DP. SYBR green-based real-time quantitative PCR assay for detection of West Nile Virus circumvents false-negative results due to strain variability. J Clin Microbiol. 2004b; 42:1511-8. [PubMed: 15070997]

Pealer LN, Marfin AA, Petersen LR, Lanciotti RS, Page PL, Stramer SL, Stobierski MG, Signs K, Newman B, Kapoor H, Goodman JL, Chamberland ME. Transmission of West Nile virus through blood transfusion in the United States in 2002. N Engl J Med. 2003; 349:1236-45. [PubMed: 14500806]

Ratterree MS, Gutierrez RA, da Rosa A.P. Travassos, Dille BJ, Beasley DW, Bohm RP, Desai SM, Didier PJ, Bikenmeyer LG, Dawson GJ, Leary TP, Schochetman G, Phillippi-Falkenstein K, Arroyo J, Barrett AD, Tesh RB. Experimental infection of rhesus macaques with West Nile virus: level and duration of viremia and kinetics of the antibody response after infection. J Infect Dis. 2004; 189:669-76. [PubMed: 14767821]

Rozen S, Skaletsky H. Primer3 on the WWW for general users and for biologist programmers. Methods Mol Biol. 2000; 132:365-86. [PubMed: 10547847]

Shi P-Y. High-Throughput Detection of West Nile Virus RNA. Journal of Clinical Microbiology. 2001; 39:1264-1271. [PubMed: 11283039]

Southam, Moore. Am J Trop Med Hyg. 1954; 3:19-50. [PubMed: 13114588]

Stramer SL, Fang CT, Foster GA, Wagner AG, Brodsky JP, Dodd RY. West Nile virus among blood donors in the United States, 2003 and 2004. N Engl J Med. 2005; 353:451-9. [PubMed: 16079368]

Tewari D, Kim H, Feria W, Russo B, Acland H. Detection of West Nile virus using formalin fixed paraffin embedded tissues in crows and horses: quantification of viral transcripts by real-time RTPCR. J Clin Virol. 2004; 30:320-5. [PubMed: 15163421]

Vanlandingham DL, Schneider BS, Klingler K, Fair J, Beasley D, Huang J, Hamilton P, Higgs S. Real-time reverse transcriptase-polymerase chain reaction quantification of West Nile virus transmitted by Culex pipiens quinquefasciatus. Am J Trop Med Hyg. 2004; 71:120-3. [PubMed: 15238700]

Whitby D, Stossel A, Gamache C, Papin J, Bosch M, Smith A, Kedes DH, White G, Kennedy R, Dittmer DP. Novel Kaposi's sarcoma-associated herpesvirus homolog in baboons. J Virol. 2003; 77:8159-65. [PubMed: 12829855]

White DJ, Kramer L, Backenson PB, Lukacik G, Johnson G, Oliver J, Howard JJ, Means RG, Campbell S, Labortory TAR, Team TSWNVR. Mosquito Surveillance and Polymerase Chain Reaction Detection of West Nile Virus, New York State. Emerging Infectious Diseases. 2001; 7:643-649. [PubMed: 11585526]

Wolf RF, Papin JF, Hines-Boykin R, Chavez-Suarez M, White GL, Sakalian M, Dittmer DP. Baboon model for West Nile virus infection and vaccine evaluation. Virology. 2006; 355:44-51. [PubMed: 16904151] 


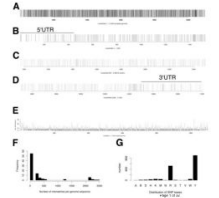

Figure 1.

SNP distribution across the WNV genome. Panel A-D SNP positions are indicated by a black bar. A, distribution across the entire genome; B, distribution across the most 5' 1,529 nucleotides; C, distribution across the E orf; D, distribution across the most $3^{\prime} 1,529$ nucleotides. E, plot of the between SNP distances on the vertical against the SNP position on the horizontal axis across the entire 11,029 WNV genome (genbank accession \# AF196835). F, Frequency histogram of the distributions of SNPs per genome. G, Distribution of base calls counted as SNP. Letters follow IUBMB nomenclature. R represents purine (A or G) and $\mathrm{Y}$ represents pyrimidine ( $\mathrm{T}$ or $\mathrm{C}$ ). 


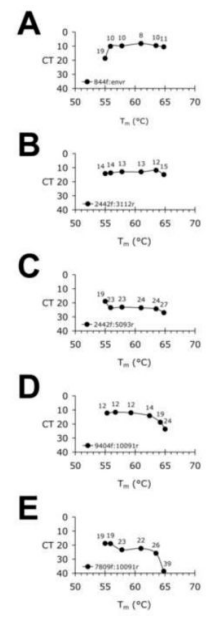

Figure 2.

Annealing temperature dependence of qPCR for individual primers pair combinations. The vertical axis is reversed as lower CTs indicate a higher target abundance or, as all reactions received the same amount of input target a higher qPCR efficiency. The horizontal axis indicated the annealing temperature. The target was cDNA from WNV strain NY99. 


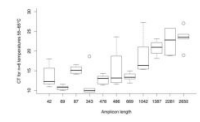

Figure 3.

Amplicon length dependence of qPCR. Boxplot of CT values at different annealing temperature (vertical axis) for primer pairs of different length (shown on the horizontal axis). Boxframe indicates the 1 and 3 quartiles, the solid bar the median and whiskers the minima and maxima. Outliers are indicated by circles. Note that the vertical axis is not to scale, but categorical. 

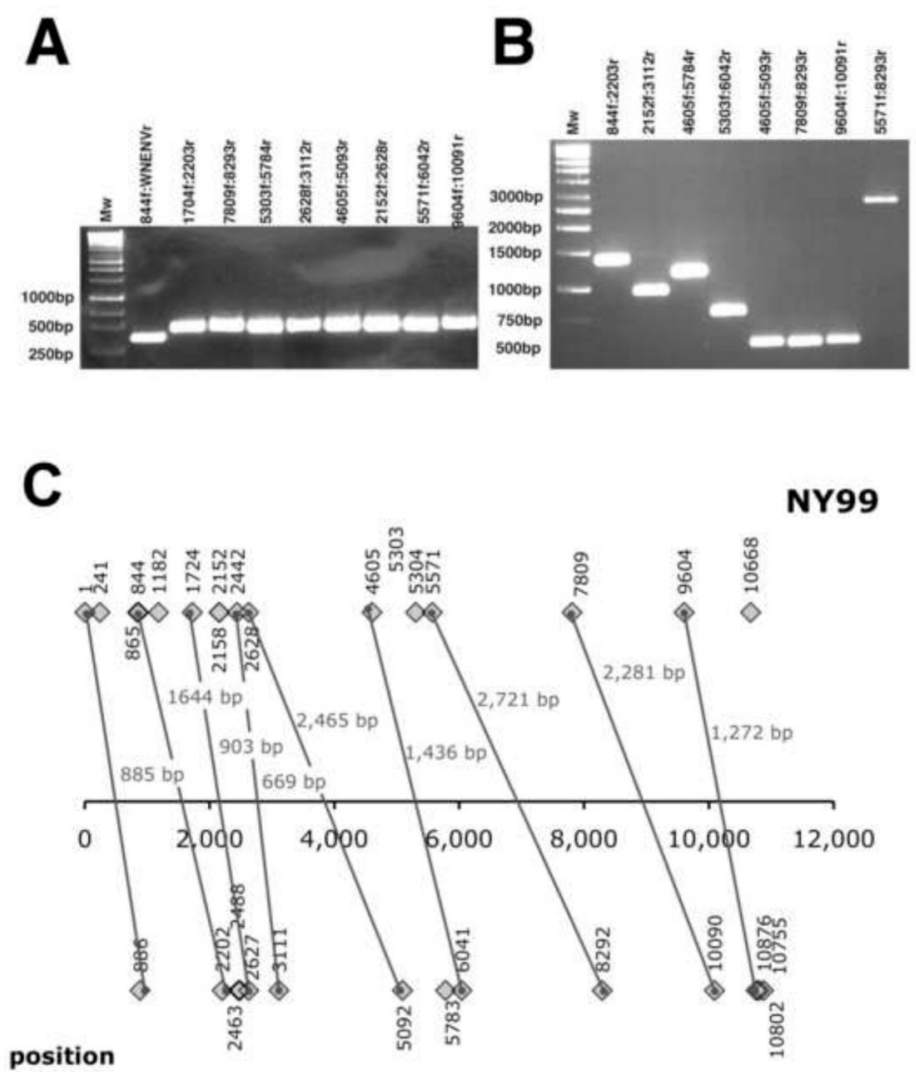

\section{Figure 4.}

Genome-wide qPCR. Picture of an ethidium bromide stained agarose gel yielding same size amplicons (A) or combinations to yield largers amplicons (B). The primer names are indicated above the gel. Note that the primer names do not indicate the map position, which can be obtained from table 1. (C) Shown are the map positions for all primers used in this study using the West Nile virus strain NY99-flamingo382-99 coordinates (genbank entry AF196835). Forward primers are above and reverse primers below the genome coordinates. Primer combinations and amplicon sizes, which were used for sequencing are indicated by vertical lines. 
A

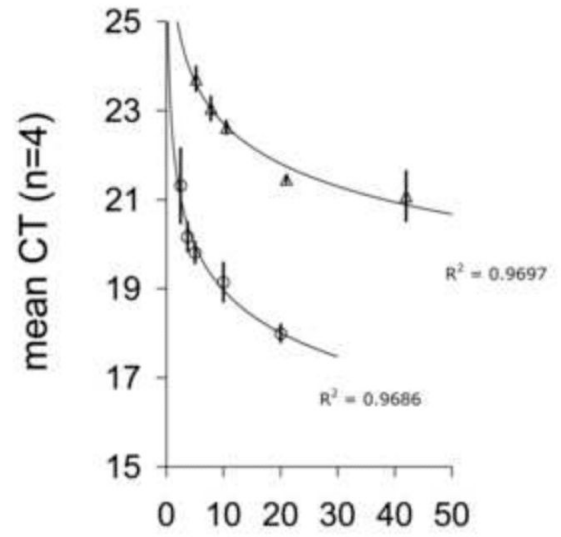

B

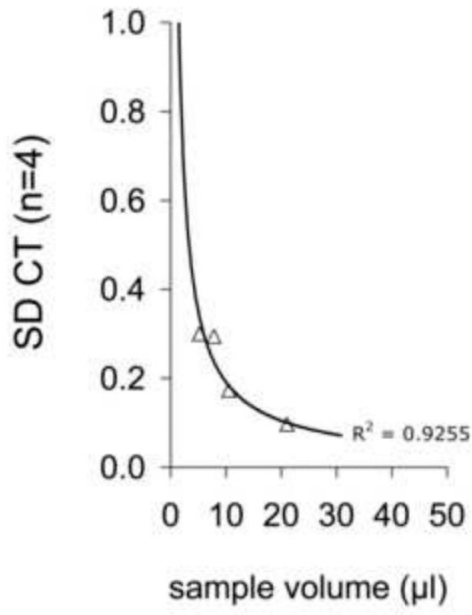

Figure 5.

Volume dependence of qPCR. (A) Shown on the horizontal axis is the amount of input cDNA sample and on the vertical axis the mean CT of four replicate measurements after real-time qPCR. Lower CT corresponds to better detection on a ${ }_{2} \log$ scale. (B) Shown is the standard deviation (SD) in CT on the vertical and input cDNA volume on the horizontal axis. 
Table 1

Primer position, name, orientation and sequence based upon NY99-flamingo382-99, complete genome (AF196835). SNP positions are underlined.

\begin{tabular}{llll}
\hline position & name & orientation & Sequence 5' to $^{\prime}$ \\
886 & wnv844r & -1 & CTCCCAAGCATCCAACCAA \\
10,876 & wnv10881r & -1 & GGGTCTCCTCTAACCTCTAG \\
10,755 & wnv3ncr & -1 & CTAGGGCCGCGTGGG \\
8,292 & wnv8293r & -1 & AGTGGGTTTCTGACCAGTCC \\
6,041 & wnv6042r & -1 & AGTCGTCTTCATTCGTGTGC \\
5,783 & wnv5784r & -1 & ATTTTGGGTACTCCGTCTCG \\
5,092 & wnv5093r & -1 & CTGCACTATCGCGCTTATGT \\
3,111 & wnv3112r & -1 & TTGACTTCACCCAGAACTGC \\
2,627 & wnv2628r & -1 & CTGATCGTAGACCGCACACT \\
2,488 & wnv2442r & -1 & GCTCTTGCCGGCTGATGT \\
2,463 & wnv2464rc & -1 & TGGCACACCCAGTGTCAGCGTG \\
2,202 & wnv2203r & -1 & GCTAGTCTCTGCGCTCCTTT \\
10,090 & wnv10091r & -1 & TGTCATCCACTCTCCTCCTG \\
1 & wnv1f & 1 & AGTAGTTCGCCTGTGTGAGCTG \\
10,668 & wnv3ncf & 1 & CAGACCACGCTACGGCG \\
1,182 & wnv1182t & 1 & TGCGTGCCCGACCATGGG \\
1,724 & wnv1724f & 1 & TAGCATTGGGCTCACAAGAG \\
2,152 & wnv2152r & 1 & CATTGGCACAAGTCTGGAAG \\
2,158 & wnv2158f & 1 & CACAAGTCTGGAAGCAGCAT \\
241 & wnv521f & 1 & GCTCTTTTGGCGTTTTTCAG \\
2,442 & wnv2442f & 1 & GCTCTTCCTCTCCGTGAACG \\
2,628 & wnv2628f & 1 & AGTGTGCGGTCTACGATCAG \\
4,605 & wnv4605f & 1 & AAAGAGAGGAGGCGTGTTGT \\
5,303 & wnv5303f & 1 & AGATGGCTGAAGCACTGAGA \\
5,304 & wnv5304f & 1 & GATGGCTGAAGCACTGAGAG \\
5,571 & wnv5571f & 1 & AGGCACTTCAGATCCATTCC \\
7,809 & wnv7809f & 1 & CAGGAAAGAAGGCAATGTCA \\
\hline 846 & wnv844f & 1 & TGGATCTTGAGGAACCCTGG \\
wnv869t & 1 & TATGCCCTGGTGGCAGCCGTC \\
\hline & wnv9404f & 1 & AAAGGGAAAGGACCCAAAGT \\
\hline
\end{tabular}

previously described in (9). 
Table 2

Theoretical amplification introduced by different RNA isolation and reverse transcription methods (assumes 1 copy WNV genome/ $\mu$ input or $10^{3}$ copies $/ \mathrm{ml}$ )

\begin{tabular}{|c|c|c|c|}
\hline Step: & Zymogen & Quiagen & Quiagen High \\
\hline \multicolumn{4}{|l|}{$\underline{\text { Sensitivity }}$} \\
\hline \multicolumn{4}{|l|}{ RNA isolation } \\
\hline input volume & $200 \mu \mathrm{l}$ & $200 \mu \mathrm{l}$ & $1000 \mu \mathrm{l}$ \\
\hline elution volume & $30 \mu \mathrm{l}$ & $50 \mu \mathrm{l}$ & $50 \mu \mathrm{l}$ \\
\hline amplification factor & $6.6 x$ & $4 \mathrm{x}$ & $20 x$ \\
\hline copies $/ \mu \mathrm{l}$ & 6.6 & 4 & 20 \\
\hline \multicolumn{4}{|c|}{$\begin{array}{l}\text { (1) } \\
\text { Low volume (standard) Reverse transcriptase (RT) }\end{array}$} \\
\hline input volume & $7 \mu \mathrm{l}$ & $7 \mu \mathrm{l}$ & $7 \mu 1$ \\
\hline final volume & $20 \mu 1$ & $20 \mu 1$ & $20 \mu 1$ \\
\hline amplification factor & $0.35 \mathrm{x}$ & $0.35 \mathrm{x}$ & $0.35 \mathrm{x}$ \\
\hline $\operatorname{copies} / \mu 1$ & 2.3 & 1.4 & 7 \\
\hline \multicolumn{4}{|l|}{ Standard QPCR: } \\
\hline maximal replicates & $3+1$ & $3+1$ & $3+1$ \\
\hline input volume & $5 \mu \mathrm{l}$ & $5 \mu \mathrm{l}$ & $5 \mu \mathrm{l}$ \\
\hline final volume & $20 \mu \mathrm{l}$ & $20 \mu 1$ & $20 \mu \mathrm{l}$ \\
\hline amplification factor & $0.25 \mathrm{x}$ & $0.25 \mathrm{x}$ & $0.25 \mathrm{x}$ \\
\hline copies/well & 12 & 7 & 35 \\
\hline \multicolumn{4}{|c|}{$\begin{array}{l}\text { (2) } \\
\text { High-capacity Reverse transcriptase (RT) }\end{array}$} \\
\hline Input volume & $30 \mu \mathrm{l}$ & $50 \mu \mathrm{l}$ & $50 \mu \mathrm{l}$ \\
\hline final volume & $100 \mu \mathrm{l}$ & $100 \mu \mathrm{l}$ & $100 \mu \mathrm{l}$ \\
\hline amplification factor & $0.33 x$ & $0.50 \mathrm{x}$ & $0.50 \mathrm{x}$ \\
\hline copies $/ \mu 1$ & 2.0 & 2.0 & 10 \\
\hline \multicolumn{4}{|l|}{ (a) Standard QPCR: } \\
\hline maximal replicates & $9+1$ & $9+1$ & $9+1$ \\
\hline input volume & $5 \mu \mathrm{l}$ & $5 \mu \mathrm{l}$ & $5 \mu \mathrm{l}$ \\
\hline final volume & $20 \mu \mathrm{l}$ & $20 \mu 1$ & $20 \mu \mathrm{l}$ \\
\hline amplification factor & $0.25 \mathrm{x}$ & $0.25 \mathrm{x}$ & $0.25 \mathrm{x}$ \\
\hline copies/well & 10 & 10 & $\mathbf{5 0}$ \\
\hline \multicolumn{4}{|c|}{ (b) High-volume QPCR: } \\
\hline maximal replicates & $4+1$ & $4+1$ & $4+1$ \\
\hline input volume & $20 \mu \mathrm{l}$ & $20 \mu \mathrm{l}$ & $20 \mu \mathrm{l}$ \\
\hline final volume & $50 \mu 1$ & $50 \mu \mathrm{l}$ & $50 \mu \mathrm{l}$ \\
\hline amplification factor & $0.4 \mathrm{x}$ & $0.4 \mathrm{x}$ & $0.4 \mathrm{x}$ \\
\hline copies/well & 40 & 40 & 200 \\
\hline
\end{tabular}

$J$ Virol Methods. Author manuscript; available in PMC 2011 October 8. 